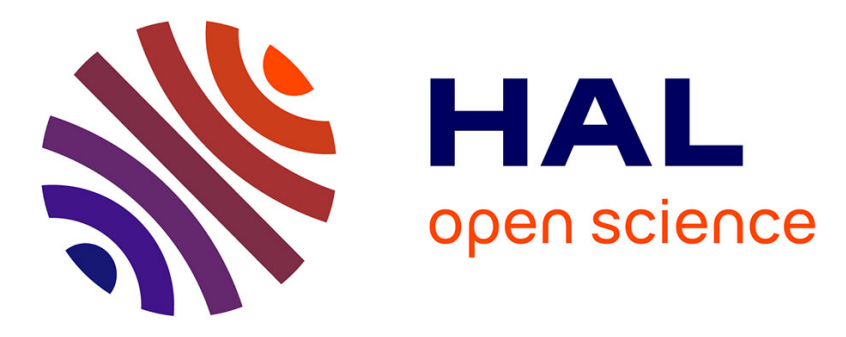

\title{
Collaborative Networks as Ways to Improve Cross-sector Collaboration in Social Innovation: An Exploratory Study
}

Michele Andréia Borges, António Lucas Soares, Gertrudes Aparecida

Dandolini

\section{To cite this version:}

Michele Andréia Borges, António Lucas Soares, Gertrudes Aparecida Dandolini. Collaborative Networks as Ways to Improve Cross-sector Collaboration in Social Innovation: An Exploratory Study. 17th Working Conference on Virtual Enterprises (PRO-VE), Oct 2016, Porto, Portugal. pp.137-147, 10.1007/978-3-319-45390-3_12. hal-01614628

\author{
HAL Id: hal-01614628 \\ https://hal.inria.fr/hal-01614628
}

Submitted on 11 Oct 2017

HAL is a multi-disciplinary open access archive for the deposit and dissemination of scientific research documents, whether they are published or not. The documents may come from teaching and research institutions in France or abroad, or from public or private research centers.
L'archive ouverte pluridisciplinaire HAL, est destinée au dépôt et à la diffusion de documents scientifiques de niveau recherche, publiés ou non, émanant des établissements d'enseignement et de recherche français ou étrangers, des laboratoires publics ou privés.

\section{(c)(1)}

Distributed under a Creative Commons Attribution| 4.0 International License 


\title{
Collaborative Networks as Ways to Improve Cross- Sector Collaboration in Social Innovation: An Exploratory Study
}

\author{
Michele Andréia Borges ${ }^{1,2}$, António Lucas Soares ${ }^{2}$ and Gertrudes Aparecida \\ Dandolini $^{1}$ \\ ${ }^{1}$ Federal University of Santa Catarina, Florianópolis, Brazil. ${ }^{2}$ Institute for Systems \\ and Computer Engineering, Technology and Science - INESC TEC, Porto, Portugal. \\ \{micheleandborges, ggtude\}@gmail.com and als@fe.up.pt
}

\begin{abstract}
Social innovation is presented as a viable alternative to incite systemic changes related to sustainability in its three dimensions (social, environmental and economic), to involve the government, companies and, above all, civil society. In order to understand the development of social innovation in Brazil and Portugal, and to promote cross-sector collaboration, we have conducted several case studies involving centers for social inovation in both countries. The data analysis demonstrates that collaboration between sectors and the construction of collaborative networks is as a key element in the development and sustainability of social innovation. In spite of this, in practice the construction of these networks is not trivial, there is the need to manage these networks innovatively. The literature review points out the key enablers for cross-sector collaboration in the context of social innovation, the alignment of values and goals, mutual trust, commitment and bridge leadership.
\end{abstract}

Keywords: Social Innovation; Cross-Sector Collaboration; Collaborative Network; Brazil; Portugal.

\section{Introduction}

Society is undergoing great changes. Problems of environmental and social order that were (apparently) "silent" a few decades ago, are today shown to all. The saturation of a strictly economic view, causes the need for the involvement of social actors to think and act systemically. As stated by Dowbor, "this implies decision-making mechanisms and management that go beyond the immediate microeconomic interest" (p. 11) [1]. Corroborating this view, Hubert [2] says that the key global challenges of today (climate change, aging, migration, among others) are both from economic and social order.

According to UN data, developed countries are faced with a new growth of income inequality [1]. Among the EU countries, Greece and Portugal have been deeply affected by the global crisis. Santos [3] states that "studies show that Portugal is trapped in an austerity crisis and is the European country where austerity measures most affect the poor, which poses special challenges for the Santa Casa Misericordia de Lisboa" (p. 
138 M. A. Borges et al.

90). In developing countries, e.g. in Latin America, Brazil is located in the deepest pit of income inequality [1].

This situation has triggered initiatives and policies promoting entrepreneurship and social innovation in these countries. According to Santos [4], the Portuguese social sector has shown that the current models of adjustment aimed to address income inequality, although they have some positive results, are not enough to account for the complexity of the problem, needing urgently to "new form of social management based on a new creative social design" (p. 86) [3]. Social innovation is presented as a viable alternative to incite systemic changes related to sustainability in its three dimensions (social, environmental and economic), involving governments, companies and, above all, civil society.

Innovation in the social sector generates productivity and economic value for the whole society. This value should be better recognised with new measurements of welfare beyond gross domestic product (GDP), as pointed out, inter alia, by the Economics Nobel Prize winner Daniel Kahneman in the American Economic Review and recently by the Stiglitz commission. According to this view, social innovations are innovations that respond to those societal challenges in which the boundary between social and economic blurs, and are directed towards society as a whole. (p. 28) [2].

The answer to these complex challenges will require the participation of actors at all levels, leading to proactive policies and an organized intervention of the various social groups [1]. Thus, more than isolated initiatives, collaboration among multiple stakeholders is the key to dissemination, effectiveness and sustainability of social innovation [4].

After a decade since the phenomenon of social innovation has established itself as a field of study [5] [6], the literature indicates that there is still a need for studies addressing the understanding of its concept, processes and diffusion [7], [8]. Studies focusing on the aspect of collaboration for social innovation are still incipient and require empirical studies in greater depth [9]. In this sense, one question emerges: how is cross-sector collaboration in social innovation initiatives developing?

In order to find preliminary answers to this research question, we explored two cases of social innovation centers, one in Portugal and the other in Brazil, aiming at achieving a preliminary understanding of cross-sector collaboration in the context of social innovation.

\section{Cross-Sector Collaboration for Social Innovation}

A literature review on the subjects of collaboration and social innovation was conducted to further examine the content of the interviews. To map and analyze the literature the Proknow-C [10] methodology was adopted. This methodology encompasses two major steps: the selection and the filtering of a set of articles. In the first step, the bibliographic databases that have adherence to the research topic are selected. Then, keywords and their combination are chosen in accordance with the search axes. Finally, the search criteria are defined, i.e., the time the articles, article type, among others. The keywords, their combinations, the limiting criteria and the selection criteria of the articles are presented in the Table below. 
Table 1. Search strategy.

\begin{tabular}{|c|c|c|c|}
\hline Keywords & Combination & Database & Search Criteria \\
\hline \multirow{5}{*}{$\begin{array}{l}\text { Social Innovation } \\
\text { Collaboration } \\
\text { Alliance } \\
\text { Partnership } \\
\text { Cooperation }\end{array}$} & $\begin{array}{l}\text { "Social Innovation" } \\
\text { AND (Collaboration }\end{array}$ & \multirow[t]{4}{*}{ Scopus } & $\begin{array}{l}\text { Fields: Title, Abstract and } \\
\text { Kevwords }\end{array}$ \\
\hline & OR Alliance OR & & Data Range: 2010 to \\
\hline & \multirow{3}{*}{$\begin{array}{l}\text { Partnership OR } \\
\text { Cooperation) }\end{array}$} & & 2015 \\
\hline & & & Document Type: article \\
\hline & & Web of Science & $\begin{array}{l}\text { Fields: Topic } \\
\text { Data Range: } 2010 \text { to } 2015 \\
\text { Document Type: article }\end{array}$ \\
\hline
\end{tabular}

The second stage of filtering the paper set is cleaning the data, resulting in a total of 86 articles for reading the titles and abstracts. The reading was made based on the research objective and meeting the criteria of empirical studies. After reading the titles and abstracts, 14 papers remained for reading in full.

Collaboration is based on the notion that problems can be solved more effectively if done by partnerships, alliances and networks [11]. It is a process in which the parties involved observe a problem from different angles, exploring their differences constructively and seeking solutions that go beyond their own limited vision of what is possible [12]. It is also a process in which new arrangements are possible by sharing resources and knowledge [11].

The results of the literature review show that for social innovation, collaboration is an important resource in understanding their complex dynamics [13], [14], [15]. It is through it that the most effective transformations occur [16]. Social innovation and collaboration have a reciprocal relationship to the extent that the collaborative processes and methods influence the social innovation impact and, in turn, social innovation creates new shapes and designs for collaboration [9]. According to Sanzo et al. [9], the existence of new forms of collaboration between sectors (government, civil society and business) is a critical feature of social innovation practices.

Thus, the ability of an inter-agency team to produce results that have a major impact on society, is built from the fortress of inter-institutional networks that allow the emergence of a new meta-institution legitimacy, resources, knowledge and sufficient strategic alignment for proper harmonization efforts within each institution [17].

In this paradigm of collaboration and inter-sectorial partnerships, private companies have led many social issues in partnership with non-profit organizations and/or government. The union of the private sector with these other sectors, towards a social goal, has shown that it is possible to work side by side and not as opponents [16]. The opposite has also been valid. Non-profit organizations working collaboratively with other sectors have achieved more success in their social enterprises. According to Shier and Handy [15]: "collaborations are supportive because they help create capacity, align goals, and focus the efforts of a nonprofit's social change agenda" (p. 21). The government, in turn, moves away from the role of mere regulator. These changes in roles and relationships are central to the effectiveness of a range of social innovations [16]. 
140 M. A. Borges et al.

An example presented by Selsky and Parker [18], about a poor educational system, illustrates how these sectors sighted and address social problems in different ways. For a business, a poor education system can represent a strategic challenge, since a failure education could result in shortages of skilled labor or training and training costs to develop a workforce. For the government, a poor educational system may reflect a lower tax revenues or managing them badly, the lack of political and administrative leadership and other impediments. For non-profit organizations, a poor educational system may indicate the need for development projects or public campaigns to keep local jobs. This example shows that when the actors from different sectors relate to the same question they are likely to think in different ways, are motivated by different objectives and employ different approaches to deal with what is in fact the same challenge. If they jointly focus efforts on this issue, a partnership project to address the poor educational system can develop. As a result, new learning can emerge and more innovative and effective solutions can be obtained as a result of the partnership and collaboration between these actors [18].

However, working together within the social action domain is not a trivial task. The process by which the cross-sector partnerships create social value is often not linear and full of weaknesses, difficulties and disappointments. Only a few partners can create social change constantly and cumulatively. Many collapse partnerships for bad account understood, incorrect allocation of costs and benefits, and distrust [19]. The challenge is to control the borders that are traded and handled within a cooperative relationship [11] so there is not only a cooperation state - "information exchange, adjustment of activities, splitting of resources and work while aiming at specific targets" (p. 1414) [20] - but also collaboration, which "involves mutual trust, in addition to being a process in which participants, working together, share information, resources, responsibilities and risks to achieve common goals" (p. 1414) [20].

When it comes to partnerships between businesses and non-profit organizations to create value and social innovation, empirical studies show that cross-sector partnerships should be cautious not to be affected by the heterogeneity of its values, missions and purposes, hampering knowledge sharing [11], [19], [21], [22]. In this sense, companies and non-profit organizations should measure efforts in aligning their partnership, since they "do not have the same agendas or the same ideological representation regarding human rights and consumer rights" [11] (p. 3).

This type of partnerships, civil-society-business, are more prone to tensions and conflicts due to their contractors institutional logic, which makes often problematic the development of the alliance [11], [19], [21], [22]. In the words of Le Ber and Branzei [19]: "Cross-sector partnerships follow nonlinear progression paths marked by constant adjustments and recombinations and punctuated by transient successes and temporary failures" (p. 145). But despite the different values and logic espoused by the authors, it is possible to innovate through cooperation and collaboration activities, without betraying the core value and the identity of the organizations [11]. This requires a collaboration between innovative multilevel, to be able to build bridges between different networks. Le Ber and Branzei [19] also suggest that the success or failure of the partnership between organization and nonprofit depends on the motivation of the partners to (re)iteratively align their roles, since the heterogeneity is inherent in this type of partnership. Moreover, they also suggest that partners sustain the momentum toward success by developing a stronger degree of relational link, especially when this 
relationship is emotionally charged, resulting in a greater exchange of knowledge and fostering co-creation for social innovation.

In this context, trust is a determining factor in the relational development of the partnership and in the sharing and dissemination of knowledge [11], [9], [23]; and that affective trust-based partnerships develop towards a greater success than those exclusively monetary [9]. Trust is nothing more than the belief in loyalty, sincerity, honesty and competence of others [24]. Sanzo et al. [9] relate to trust the three elements: capacity, honesty and benevolence. The capacity refers to the necessary experience and competencies in the partnership to carry out the work effectively. Honesty it is the fulfillment of the promises and adherence to the principles of the parties. Benevolence is the interest in the well-being that the parties have for each other [9]. The more you develop a trust in partnerships the more collaboration becomes intense and effective. This means a greater exchange of experiences and knowledge, which are favorable for innovation [11]. In other words, trust leads to a more successful collaboration which, in turn, creates more confidence in the partnership, which is then enhanced, leading to a virtuous circle of collaboration through the creation of new capital. This capital is made up of individuals moving between multiple networks and bring with them knowledge and influence of social ties that are leveraged to raise original solutions to complex problems [11].

Trust can be raised also by a Bridge Leadership. According to studies of Manning and Roessler, Mcmullen and Adobor and Raišiene collaborative partnerships they had a bridge leadership they were developed better than those who did not have [25], [26], [27]. A bridge leadership is an individual who connects through alternative ways, organizations can be widely disparate in wealth, power, culture, language, values, interests, and structural characteristics. This kind of leader has great ability to raise the confidence of the people and organizations in which he makes the bridge. This is due to their competence, integrity, perseverance and empathy, as well as their ability to involve different types of people, be open to compromise, have credibility with their constituents and an aptitude to learn to understand the language used by stakeholders [26].

Just as trust, commitment between partners is another key element to the success of cross-sector partnership [9]. Commitment is the belief that the relationship between the parties is sufficiently important enough to expend the maximum effort to maintain the partnership. There are two basic types of commitment [9]: calculative and affective. The first is based on a rational assessment of the benefits and costs of a particular relationship. The second takes an emotional predisposition to maintain the relationship because of an emotional bond with their partner, often as a result of the congruence of values that you have with him. Sanzo et al [9] says that affective commitment is, for most researchers, the factor that has the greatest influence to maintain mutually beneficial relationships.

The existence of trust and commitment increases the attitudes and behaviors of participants, encouraging and promoting collaboration, creativity, information sharing and knowledge [9], the value creation and social innovation [11], [19].

Summarising, the alignment and realignment of values and goals, the achievement of higher levels of trust and commitment, and the role of the Leadership Bridge, are enablers that support cross-sector collaboration process. Figure 1 summarizes all those elements. 
142 M. A. Borges et al.

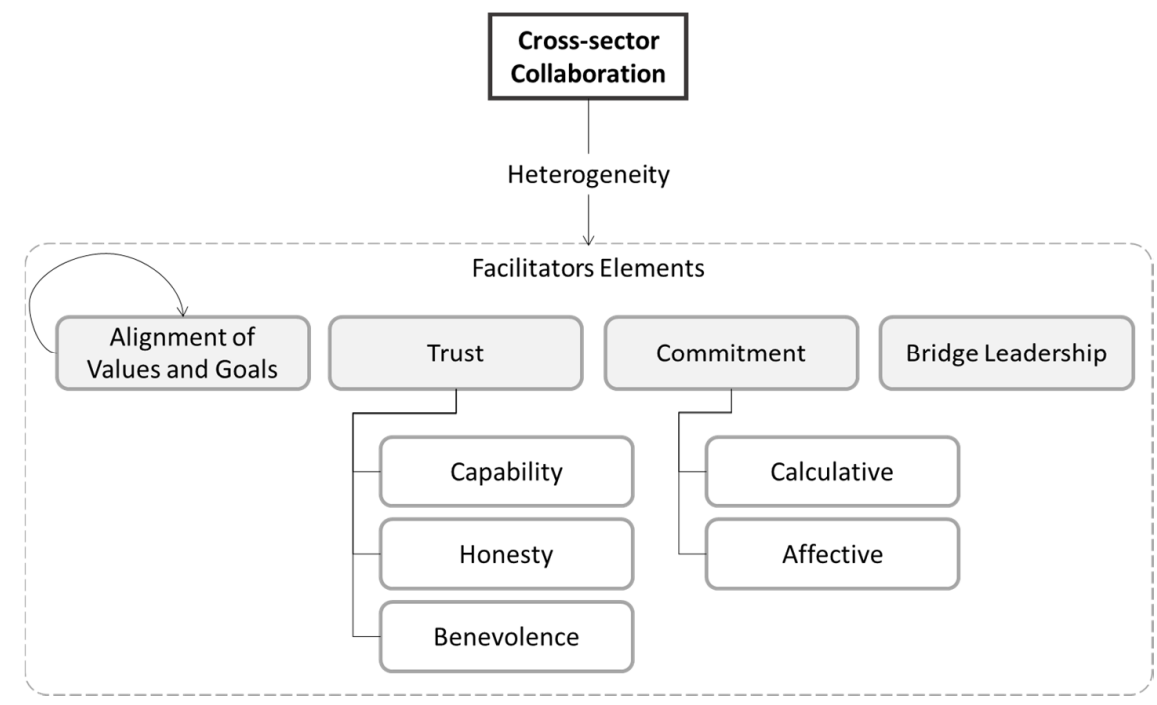

Fig. 1. Key enablers cross-sector collaboration.

The realignment, trust and commitment progress according to the maturity of the relationship over collaboration continuum, which can lead to a successful partnership [19] and creation or consolidation of collaborative networks. According Camarinha Matos, the collaborative network is defined as:

Is a network consisting of a variety of entities (e.g. organizations and people) that are largely autonomous, geographically distributed, and heterogeneous in terms of their operating environment, culture, social capital and goals, but that collaborate to better achieve common or compatible goals, and whose interactions are supported by computer network (p. 4) [28].

\section{Exploratory Cases}

In order to achieve a preliminary understanding of cross-sector collaboration in the context of social innovation, two cases were explored through the perception of managers of two centers for social innovation (CSI), one in Portugal and the other in Brazil. Data collection was conducted through face-to-face interviews.

The CSI investigated in Brazil is located in the south of the country and is characterized by supporting socially innovative initiatives, offering space and free services to people who want to make a difference in the region in which it is located. Born in 2011, from a demand from NGOs, social entrepreneurs, students, researchers and social investors who needed a place to think and act creatively in the public interest and the common good. Is inspired by the innovative models of the Centre for Social Innovation, Canada.

The CSI in Portugal is located in the north of the country and also originated in 2011, by a local authority and a social foundation. The goal of the CSI is to promote the 
implementation of innovation projects and social entrepreneurship in the city which it is based.

The average duration of interviews was 30 minutes. Although the interview had an open character, it was taken as based on three guiding questions, which include the focus and purpose of this study: How is developing the Social Innovation in Brazil/Portugal in particular regarding the collaboration between the different sectors

of society involved (public, private, civil society)? What are the trends regarding to this in Brazil/Portugal?

For transcription and content analysis a qualitative and mixed methods data analysis tool was used MAXQDA ${ }^{\mathrm{TM}}$ ref.

\subsection{Cross-sectorial Collaboration in Social Innovation: The Vision of CSI Brazil}

The interest of social innovation in Brazil, according to the CSI interviewed, has been growing. By analysing the activities in recent years in the Social Good Brazil social network (an organization that connects and supports individuals and organizations in the use of technology, new media and innovative behavior to contribute to solving social problems), an increasing number in the interest of the people by the theme social innovation has been observed.

Civil society organizations have been engaged in initiatives that promote the development of their communities. Private companies have also begun to work with the third sector organizations. However, when it comes to collaboration between sectors (private and third sector), the initiatives are still incipient.

At the core of CSI Brazil there is the issue of cross-sector collaboration and in this sense, they have worked in the union of collaborative partnerships, through the restructuring of a "Portal Transparência" project, whose goal is to make private companies aware of socially innovative ideas promoted by institutions of the third sector. The idea, organizational structure and impact of the action of third sector initiatives are evaluated in order to have a quality seal these initiatives, creating a relationship of trust with companies interested in collaborating.

This CSI project arose from the very necessity of non-profit organizations, once they realized the difficulty of private enterprises to trust and collaborate with their projects. CSI through a process of co-creation with the various social actors (organizations, entrepreneurs, students, etc.) is redesigning this "Portal Transparência" project.

While it is growing interest in the topic, the effectiveness of actions and the process of collaboration between the sectors challenges the future of social innovations in Brazil.

\subsection{Cross-sectorial Collaboration in Social Innovation: The Vision of CSI Portugal}

In the last five years there has been a setback for the development of social innovations. This setback is linked with some political discontinuities, since innovation projects in the social sphere were to be, in many cases experienced by the central government or the local government (municipal authorities). 
144 M. A. Borges et al.

However, 20 years ago, experiments with social innovation projects provided significant learning regarding the labor issues in public partnerships and private organizations from the third sector, as well as the tangible and intangible issues in the development of the territories. These experiments showed the need for networking and collaboration.

Under the perspective of the Portuguese CSI, the collaborative work between CSIs is an innovation in itself which demands overcoming many challenges and difficulties. The Portuguese CSI has, in this sense, experimented several models for innovation governance, integrating the various sectors (public, private and third sector).

At this time the reality and complexity of the problems, the lack of funding, a crisis, in fact, require other types of innovation in governance models, much aiming at policy integration and integrated intervention in the territories rather than focused [ in each of] different sectors" (manager of the CSI Portugal).

Thus, collaboration and inter-sectorial partnerships are key to a promising direction of social innovations. The partnership of CSI Portugal with international projects within the European Union (EU), demonstrates this fundamental quality of collaboration and sharing of knowledge in social innovation projects. "The EU in this respect is a super interesting work from the point of view of us put together" (manager of the CSI Portugal).

However, cross-sector collaboration and sharing of knowledge is a challenge to be overcome.

It's hard to be able to share. And these issues of innovation, and we have some ability to be humble and to see what is what the neighbor be doing or trying to find that we are reinventing the wheel" (manager of the CSI Portugal). [...] Each one has a vision. Each of one us does not like to get out of its comfort zone. We share only up to a point. Either we change and we break with this logic or it is very difficult to innovate" (manager of the CSI Portugal).

\subsection{Barriers and Future Challenges to Cross-sectorial Collaboration in Social Innovation}

CSI Brazil and the CSI Portugal have a close view of the barriers and challenges in cross-sectorial collaboration in Social Innovation.

Barriers to social innovation and cross-sectorial collaboration:

- Difficulty in measuring the impact of initiatives.

- Many social interventions are deployed by associations and organizations whose volunteers frequently don't have some management skills.

- Social innovation can be seen as a hype. On the one hand, by becoming fashionable, the critical mass increases and the debate and discussion about the topic is encouraged. On the other hand, everyone ends up calling social innovation to any intervention that is made in the social sphere because it is fashionable to do so. There is no concern to understand and deepen the concept of what actually comes to be a social innovation.

- Difficulty working collaboratively. Everyone wants to be on your very confined space. 
- Private companies want to be protagonists of the shares.

- The entrepreneurs think only from their perspective, without worrying about what people want to they will work want.

Future challenges for social innovation and cross-sectorial collaboration:

- Break up with the idea of many entrepreneurs in the social area and anyone can intervene or give feedback.

- Break away from the paternalistic vision.

- Empower citizens so that they are agents of transformation and that they can work collaboratively with the State for the promotion of public policies. The need of the institutions realized that they are a company that has to innovate within this social movement and it has to innovate in their management models in their entry strategies in the Market.

- Transform initiatives in social business.

- Work with the beneficiaries. Understand your needs and give fact they need an innovation.

- Working in collaboration with other sectors.

\section{Discussion and Conclusion}

Brazil and Portugal have an historical relationship of colonization and, although this has determined the adoption of some cultural aspects from the former colony, they are today countries that differ considerably in terms of economy and social development. However, global challenges and the global crisis have promoted the engagement of both the developed countries, as in the developments in driving new solutions to these challenges facing.

The content analysis of the interviews showed that these two CSI converge as ideas and as the perception of the development of social innovation. Both believe that collaboration and sharing of information and knowledge between the different sectors are the key to the direction of social innovations. Collaborative processes involving the sectors (governmental, profit and non-profit) the beneficiary communities can result in innovations that, in fact, contribute to the development of the territories. In this process, there is an exchange that fosters the process of improving project management by the organizations involved in social innovation.

Mechanisms of mediation and estimation of the impacts, and the professional management of initiatives through non-profit organizations are also challenges for social innovation. While the improvement in mediating the impacts and conduct of initiatives in social business aspect can cooperate in forming collaborative partnerships with other organizations, it provides the transparency of actions, generating more mutual trust between organizations.

The experiences of CSI investigated corroborate the empirical studies carried out at the international level. The research study indicate that collaboration is very important 
146 M. A. Borges et al.

to bring solutions that go beyond the limited vision of a single individual, group or organization, and to transform the most effective and sustainable actions.

The culture for collaboration is relatively recent, it came with the era of knowledge and information and communication technologies [3]. In practice, the culture of collaboration demand efforts to establish itself in the daily lives of people and organizations, and it involves trust, commitment and alignment of values and goals. The higher the degree of trust and commitment will be greater knowledge sharing among actors [14].

Thus, this research contributes to the understanding of the challenges and key elements that can help advance the field as scientific knowledge, but also as shares of empirical reality.

\section{Acknowledgment}

This work was conducted during a scholarship supported by the Doctoral Sandwich Abroad Program CAPES/PDSE at the Federal University of Santa Catarina. Financed by CAPES - Higher Education Personnel Improvement Coordination within the Ministry of Education of Brazil.

\section{References}

1. Dowbor, L.: Inovação social e sustentabilidade. Econ. Glob. E Gestão. 12, 933 (2007).

2. Hubert, A..: Empowering people, driving change - Social innovation in the European Union. (2010).

3. Santos, R.T.: Social innovation oriented towards solving practical problems: The case of the Santa Casa da Misericórdia de Lisboa. In: Viñals, C.R. and Rodríguez, C.P. (eds.) Social Innovation: New forms of organisation in knowledge-based societies. Pp. 84-107. Routledge - Taylor \& Francis Group, London and New York (2013).

4. Klein, J.L., Fontan, J.M., Harrisson, D., Lévesque, B.: The quebec system of socia 1 innovatio $n$. A focused analysis on the local development field. Finisterra. 47, 9-28 (2012).

5. Murray, R., Caulier-Grice, J., Mulgan, G.: The Open Book of Social Innovation. The Young Foundation/National Endowment for Science, Technology and the Art - NESTA (2010).

6. Mulgan, G.: The Process of Social Innovation. Innov. Technol. Governance, Glob. 1, 145-162 (2006).

7. Cajaiba-Santana, G.: Social innovation: Moving the field forward. A conceptual framework. Technol. Forecast. Soc. Change. 82, 42-51 (2014). 
8. Mulgan, G.: Collaboration and collective impact: how can funders, NGOs and governments achieve more together? NESTA. (2006).

9. Sanzo, M.J., Álvarez, L.I., Rey, M., García, N.: Business-nonprofit partnerships: a new form of collaboration in a corporate responsibility and social innovation context. Serv. Bus. 1-26 (2015).

10. Ensslin, L., Ensslin, S.R., Lacerda, R.T.O., Tasca, J.E.: Processo de Seleção de Portfólio Bibliográfico, (2010).

11. Harrisson, D., Chaari, N., Comeau-Vallée, M.: Intersectoral Alliance and Social Innovation: When Corporations Meet Civil Society. Ann. Public Coop. Econ. 83, 1-24 (2012).

12. Gray, B.: Collaborating: Finding common ground for multiparty problems. Jossey Bass, San Francisco (1989).

13. Goldenberg, M.: Social Innovation in Canada: How the non-profit sector serves Canadians... And how it can serve. Canadian Policy Research Networks Inc. (CPRN), Ontario (2004).

14. Westley, F., Zimmerman, B., Patton, M.: Getting to Maybe: How the World is Changed. Random House of Canada Ltd., Toronto (2006).

15. Shier, M.L., Handy, F.: Social Change Efforts of Direct Service Nonprofits: The Role of Funding and Collaborations in Shaping Social Innovations. Hum. Serv. Organ. Manag. Leadersh. Gov. 39, 6-24 (2015).

16. Phills, J., Deiglmeier, K., Miller, D.: Rediscovering social innovation. Stanford Soc. Innov. Rev. Fall, 34-43 (2008).

17. Hernández, I.D., Sánchez, O.: Innovación social abierta en el diseño de una política y estrategia de formalización sostenible: un caso colombiano de gobierno colaborativo. Rev. Fac. Ciencias Económicas. 22, 47-61 (2014).

18. Selsky, J.W., Parker, B.: Platforms for Cross-Sector Social Partnerships: Prospective Sensemaking Devices for Social Benefit. J. Bus. Ethics. 94, 21-37 (2011).

19. Le Ber, M.J., Branzei, O.: (Re)Forming Strategic Cross-Sector Partnerships: Relational Processes of Social Innovation, (2010).

20. Ferreira, R.P., Silva, J.N., Strauhs, F.R., Soares, A.L.: Performance Management in Collaborative Networks: a Methodological Proposal. J. Univers. Comput. Sci. 17, 1412-1429 (2011).

21. Le Ber, M.J., Branzei, O.: Value Frame Fusion in Cross Sector Interactions. J. Bus. Ethics. 94, 163-195 (2010).

22. Harrisson, D., Comeau-Vallée, M., Chaari, N.: Analyse d'une Pratique innovante Intersectorielle. Entreprise Publique et Associations de Défense des 
148 M. A. Borges et al.

Droits des Consommateurs. Finisterra. XLVII, 29-48 (2012).

23. Kolleck, N.: Innovations through networks: understanding the role of social relations for educational innovations. Zeitschrift für Erziehungswiss. 17, 4764 (2014).

24. Zucker, L.G.: Production of trust: Institutional sources of economic structure, 1840-1920. Res. Organ. Behav. 8, 53-111 (1986).

25. Manning, S., Roessler, D.: The Formation of Cross-Sector Development Partnerships: How Bridging Agents Shape Project Agendas and Longer-Term Alliances. J. Bus. Ethics. 123, 527-547 (2013).

26. Mcmullen, R.S., Adobor, H.: Bridge leadership: a case study of leadership in a bridging organization. Leadersh. Organ. Dev. J. 32, 715-735 (2011).

27. Raišienè, A.G.: Sustainable development of interorganizational relationships and social innovations. J. Secur. Sustain. ISSUES. 2, 65-76 (2012).

28. Camarinha-Matos, L.M., Afsarmanesh, H.: Collaborative Networks: value creation in a knowledge society. In: PROLAMAT'06 IFIP Int. Conf. On Knowledge Enterprise - New Challenges, Shanghai, China, Jun 2006, Springer. 